\title{
Advantage of recording single-unit muscle sympathetic nerve activity in heart failure
}

\author{
Hisayoshi Murai *, Masayuki Takamura and Shuichi Kaneko \\ Department of Disease Control and Homeostasis, Graduate School of Medical Science, Kanazawa University, Kanazawa, Japan
}

\section{Edited by:}

Elisabeth Lambert, Baker IDI Heart and Diabetes Institute, Australia

\section{Reviewed by:}

Vaughan G. Macefield, University of Western Sydney, Australia

Olaf Grisk, University of Greifswald, Germany

\section{*Correspondence:}

Hisayoshi Murai, Department of Disease Control and Homeostasis, Graduate School of Medical Science, Kanazawa University, 13-1

Takara-Machi, Kanazawa 920-8641, Japan.

e-mail: sakurasoma1209@yahoo.co.jp
Elevated sympathetic activation is a characteristic feature of heart failure (HF). Excessive sympathetic activation under resting conditions has been shown to increase from the early stages of the disease, and is related to prognosis. Direct recording of multiunit efferent muscle sympathetic nerve activity (MSNA) by microneurography is the best method for quantifying sympathetic nerve activity in humans. To date, this technique has been used to evaluate the actual central sympathetic outflow to the periphery in HF patients at rest and during exercise; however, because the firing occurrence of sympathetic activation is mainly synchronized by pulse pressure, multiunit MSNA, expressed as burst frequency (bursts/min) and burst incidence (bursts/100 heartbeats), may have limitations for the quantification of sympathetic nerve activity. In HF, multiunit MSNA is near the maximum level, and cannot increase further than the heartbeat. Single-unit MSNA analysis in humans is technically demanding, but provides more detailed information regarding central sympathetic firing. Although a great deal is known about the response of multiunit MSNA to stress, little information is available regarding the responses of single-unit MSNA to physiological stress and disease. The purposes of this review are to describe the differences between multiunit and single-unit MSNA during stress and to discuss the advantages of single-unit MSNA recording in improving our understanding the pathology of increased sympathetic activity in HF.

Keywords: sympathetic nerve activity, heart failure, exercise, arrhythmia

\section{INTRODUCTION}

Augmented sympathetic nerve activity is a characteristic feature of heart failure (HF). Excessive sympathetic activation under resting conditions has been shown to increase from the early stages of the disease, and elevated levels of sympathetic nerve activity are correlated with a poor prognosis (Cohn et al., 1984; Francis et al., 1990; Grassi et al., 1995; Barretto et al., 2009). Sympathetic activity plays an essential role in maintaining blood pressure in acute HF, but excessive sympathetic activity in chronic HF has deleterious effects on the heart, including beta receptor downregulation (Bohm et al., 1997), cardiac myocyte apoptosis (Communal et al., 1998), and calcium overload (Chaudhri et al., 2002).

Although sympathetic nerve activity is difficult to assess in clinical settings, the assessment of sympathetic nerve activity is considered important in human HF. Although it has been 40 years since Vallbo and Wallin (Sundlof and Wallin, 1977; Vallbo et al., 1979) developed microneurography to record multiunit efferent muscle sympathetic nerve activity (MSNA) directly, it is still considered the best method for quantifying sympathetic nerve activity in healthy human subjects and in those with diseases associated with cardiovascular risk. Since the first report of the use of microneurography in human HF in 1986 (Leimbach et al., 1986), many groups have applied this technique to evaluate the actual central sympathetic outflow to the peripheral vascular bed in HF patients at rest and during exercise. However, as the firing occurrence of sympathetic activation is mainly synchronized by pulse pressure, multiunit MSNA may have limitations in the quantification of sympathetic nerve activity. Single-unit MSNA analysis in humans was refined by Macefield et al. (1994). This technically demanding method requires adjustment of the tungsten electrode until a large unitary discharge is observed in a raw nerve action potential signal to discriminate a single-unit action potential. Although a great deal is known about the response of multiunit MSNA during stress, little information is available regarding the response of single-unit MSNA to stress. The purpose of this review is to describe the differences between multiunit and single-unit MSNA during stress and to discuss the advantages of single-unit MSNA recording.

\section{DIRECT RECORDING OF MUSCLE SYMPATHETIC NERVE ACTIVITY IN HUMAN SUBJECTS \\ ASSESSMENT OF MULTIUNIT MSNA AND ITS LIMITATIONS}

Traditionally, multiunit MSNA is quantified by counting the number of bursts during a specified period of time and 100 heart beats (Sundlof and Wallin, 1977). As multiunit MSNA is mostly regulated by arterial baroreceptors, burst occurrence is synchronized with the cardiac interval (Figure 1). Pulse synchronous bursts are a specific feature of MSNA, which is different from skin sympathetic nerve, sudomotor nerve, or motor nerve activity. However, under conditions of augmented sympathetic excitation, including HF, essential hypertension, or obstructive sleep apnea, the frequency of synchronized MSNA is near the maximum response level to sympathoexcitatory stimulation (i.e., 100 bursts per 100 heart beats). To break through this limitation, total MSNA and/or normalized 
amplitude measurements have been utilized. Total MSNA is calculated as the product of the burst rate and the burst amplitude per minute, with all amplitudes normalized to the maximum amplitude (Sundlof and Wallin, 1977). The normalization process of absolute burst amplitudes has been shown to be a reproducible variable (Kimmerly et al., 2004). This approach assumes that the burst of greatest amplitude reflects maximal recruitment of active neurons for that particular recording site. However, this approach cannot be used to compare subjects or to compare the same subject on different occasions, when the intervention changes the burst amplitude (i.e., shifts the distribution), because the normalization procedure will eliminate the change (Burke et al., 2011). In addition, total multiunit MSNA cannot distinguish between changes in sympathetic nerve firing due to the recruitment of additional single-unit vasoconstrictor neurons and that due to an increase in firing rate of already active single-unit fibers.

\section{SINGLE-UNIT MSNA ANALYSIS IN HEALTHY HUMANS AND IN VARIOUS DISEASE STATES}

Macefield et al. (1994) refined single-unit MSNA analysis. This technically demanding method requires adjustment of the tungsten electrode until a large unitary discharge can be observed in a raw nerve action potential signal to discriminate a single-unit action potential (Figure 1). However, the technique provides an estimate of single-unit firing properties in relation to the number of active firings and/or the recruitment of fibers from central or reflex effects. Using this technique, additional measurements can be obtained with regard to the mean firing frequency, the firing probability (the percentage of cardiac intervals in which a unit fires), and the percentage of spikes a unit generates per cardiac interval. Single-unit MSNA describes three possible scenarios to explain an increase in sympathetic outflow: (1) an increase in overall mean spike firing frequency without an increase in the rate of multiple firings per cardiac interval; (2) an increase in the firing frequency by multiple spike firing within one cardiac interval; and (3) the recruitment of additional neurons (Macefield et al., 2002; Figure 2). Macefield et al. (1999) demonstrated that single-unit MSNA tends to fire only once per cardiac interval even under conditions associated with elevated sympathetic nerve activity such as HF, suggesting that single-unit MSNA has the capacity to increase multiple spike firing within one cardiac interval in a state of intense sympathoexcitation. We demonstrated that singleunit MSNA can also be recorded during periods of physiological stress [e.g., handgrip ( $\mathrm{HG}$ ) exercise and the Valsalva maneuver] and that reflex sympathoexcitation could be attributed to changes in the frequency of single-unit spike firing within each multiunit sympathetic burst in healthy subjects. In particular, the firing of multiple spikes within one cardiac interval was significantly augmented during the Valsalva maneuver (Murai et al., 2006). The firing of these instantaneous multiple spikes is thought to influence strong effector organ responses. In fact, acute irregular and rapid nerve stimulation has been shown to evoke a greater effector organ response than regular stimulation through increased norepinephrine release in anesthetized rats (Dibona and Sawin, 1999).

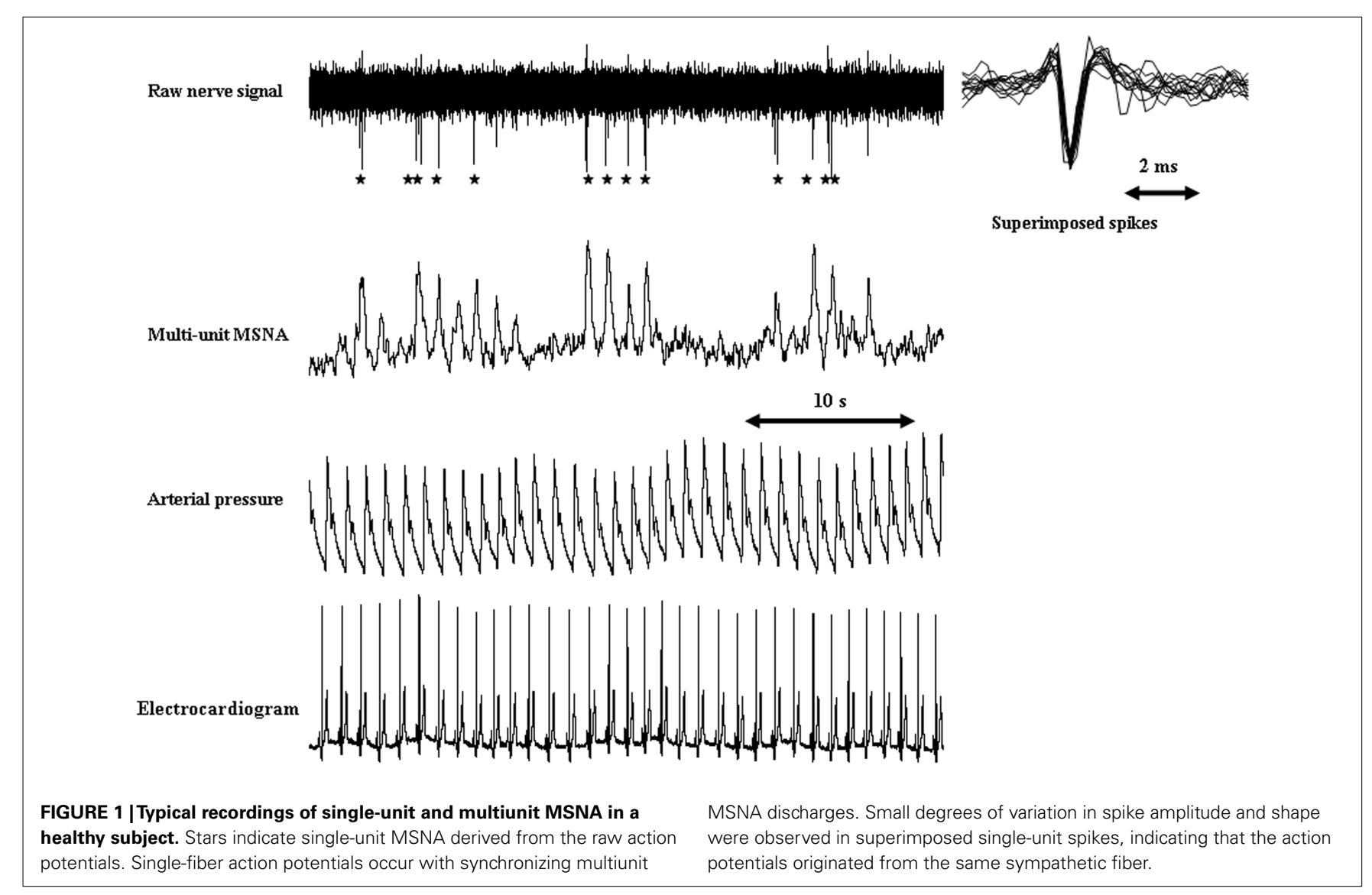




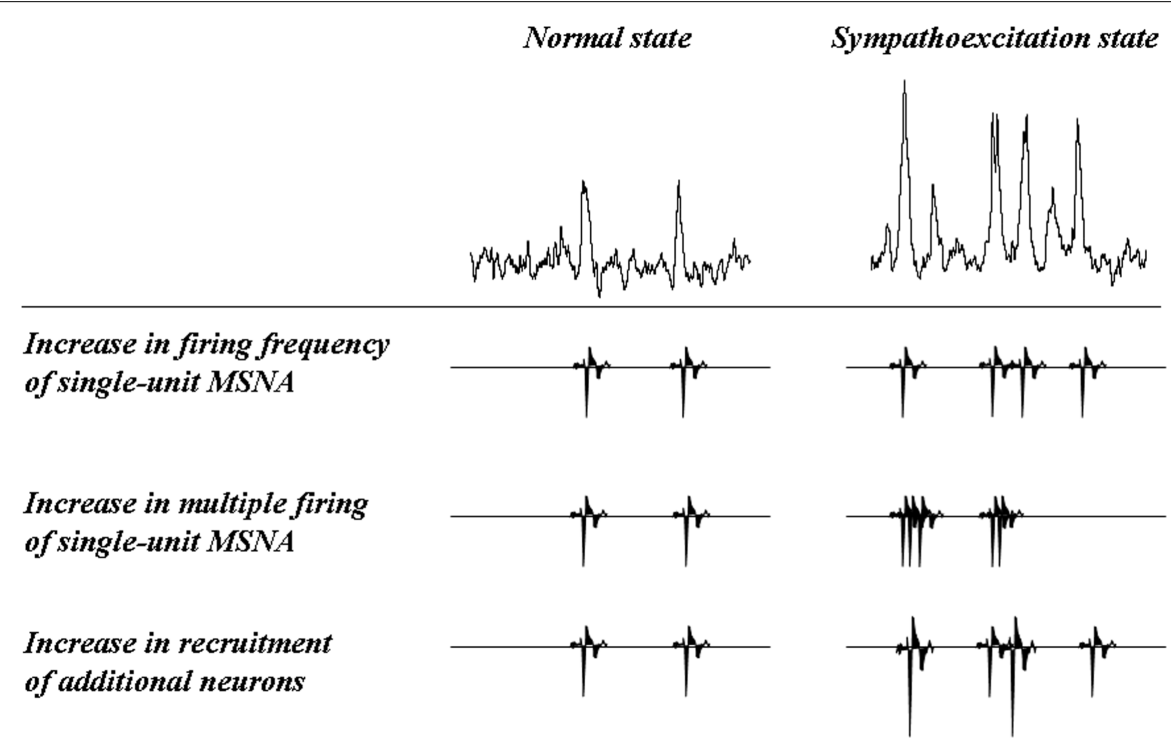

FIGURE 2 | Increases in burst intensity: potential mechanisms. Schematic representation of the three mechanisms that can bring about an increase in sympathetic burst intensity (from Macefield et al., 2002).

Lambert et al. (2011) reported that the incidence of multiple firing was positively correlated to cardiac norepinephrine spillover in humans. These results suggest that an instantaneous increase in the frequency of single-unit firing during one cardiac interval provides additional and accurate information on efferent sympathetic firing, which cannot be determined by multiunit MSNA analysis. The multiple firing frequency of single-unit MSNA may be related to disease progression. Recent research has shown that a resting high firing frequency or incidence (percentage) of multiple spikes is related to cardiovascular risk factors, including hypertension (Lambert et al., 2008), type 2 diabetes mellitus (Huggett et al., 2005), obstructive sleep apnea (Elam et al., 2002), panic disorder (Lambert et al., 2006), myocardial infarction (Graham et al., 2004), and congestive HF (CHF; Macefield et al., 1999; Murai et al., 2009).

\section{ASSESSMENT OF MUSCLE SYMPATHETIC NERVE ACTIVITY DURING EXERCISE ROLE OF SYMPATHOEXCITATION DURING EXERCISE}

At low levels of exercise, cardiac output is increased by the withdrawal of parasympathetic nerve activity, contributing to an increase in heart rate. However, the reflex response of parasympathetic withdrawal to low levels of exercise cannot meet the demand for rapid delivery of oxygen to exercising skeletal muscle during intense exercise. Exercise-induced sympathetic activity plays a key role in the redistribution of cardiac output toward active skeletal muscle (Mitchell, 2012). The reflex response of sympathetic nerve activity to exercise is evoked by central command, mechanical deformation of afferent receptive fields (muscle mechanoreflex), and metabolic byproducts during contraction (muscle metaboreflex) in thin fiber muscle afferents (Kaufman and Hayes, 2002; Williamson et al., 2006; Mitchell, 2012).

In healthy subjects, the sympathetic nervous system effectively adjusts to intense exercise at the cardiac and peripheral levels to meet the metabolic demands of exercising muscle. However, in HF patients, heart rate and sympathetic nerve activity are already augmented at rest. The failing heart is left with limited inotropic and chronotropic reserves to respond to the demands for increased cardiac output. In a microneurographic study, Notarius et al. (1999) reported that the resting level of multiunit MSNA was negatively correlated with the peak $\mathrm{VO}_{2}$ in $\mathrm{HF}$, suggesting that sympathetic nerve activity in HF contributes to exercise intolerance as well as a poor prognosis. In fact, during exercise in HF, augmented sympathoexcitation and sympathetically mediated excess peripheral vasoconstriction were observed (Zelis et al., 1974; LeJemtel et al., 1986; Middlekauff et al., 2000; Momen et al., 2004). These factors are thought to contribute to a reduced exercise capacity in HF (Piepoli et al., 1996; Crisafulli et al., 2007).

\section{MULTIUNIT AND SINGLE-UNIT MSNA RESPONSE DURING STATIC EXERCISE IN HF}

Since the development of microneurography, the increased response of multiunit MSNA was considered to indicate elevated central sympathetic nerve activity to the peripheral vascular bed. Augmented response of multiunit MSNA to handgrip exercise and its mechanism were reported previously in healthy human subjects (Mark et al., 1985). However, there was controversy with regard to the differences in reflex response of multiunit MSNA to HG exercise between HF patients and age-matched healthy controls.

Notarius et al. (2001) reported the response of multiunit MSNA to HG exercise in chronic $\mathrm{HF}(\mathrm{EF}=19 \%)$. They examined the multiunit burst frequency during $2 \mathrm{~min}$ of $30 \%$ isometric $\mathrm{HG}$ and post-HG ischemia in 14 chronic HF patients compared to 10 healthy subjects, and found an augmented response of MSNA, expressed as burst frequency and incidence, to HG exercise in chronic HF.

Sterns et al. (1991) compared the response of multiunit MSNA between nine chronic HF (EF <20\%) patients and eight healthy subjects. They demonstrated that the percent change in total 
MSNA expressed as the multiunit MSNA frequency multiplied by the burst amplitude during $2 \mathrm{~min}$ of $30 \% \mathrm{HG}$ exercise tended to be decreased in chronic HF patients compared to healthy subjects. In addition, they found significant blunting during post-HG ischemia, indicating that muscle metaboreceptor responses were blunted in chronic HF.

In addition, Negrao et al. (2001) examined multiunit MSNA frequencies using the same method and performed a comparison between 24 severe HF patients $(\mathrm{EF}=29 \%), 24$ mild HF patients $(\mathrm{EF}=35.6 \%)$, and 10 healthy controls. Their results indicated that the response of multiunit MSNA did not differ between the three groups.

It is likely that the responses of multiunit MSNA are dependent on disease severity, race, sex, and intensity of exercise. However, these controversial results may be attributable to the limitations of multiunit MSNA. In CHF, the level of multiunit MSNA is nearly maximal at rest, so the frequency of pulse synchronized MSNA cannot increase further. That is, burst incidence cannot increase above 100 bursts/100 heartbeats because of pulse synchrony.

Thus, single-unit MSNA analysis is useful for determining actual sympathetic neural firing within one cardiac interval. In $\mathrm{HF}$ at rest, despite the elevated level of multiunit MSNA, the incidence of multiple firing of single-unit sympathetic spikes was not different, but the firing frequency of single-unit MSNA was significantly increased compared to healthy subjects (Macefield et al., 1999). However, we recently demonstrated that the percentage of multiple single-unit spikes within one cardiac interval was increased during HG exercise in chronic HF patients compared to healthy subjects, although the response of multiunit MSNA was not significantly different between the two groups (Murai et al., 2009; Figure 3). In particular, there was a decrease in the percentage of cardiac intervals that contained one spike (from $74 \pm 2$ to $61 \pm 2 \%, P<0.05)$ and an increase in the proportion of cardiac intervals that had two and three spikes (from $20 \pm 2$ to $28 \pm 2 \%$ and from $5 \pm 1$ to $10 \pm 1 \%$, respectively, $P<0.05$ ) between baseline and HG exercise in CHF patients (Figure 4). These results suggest that single-unit MSNA responses contributed to the exaggerated sympathoexcitation measured during exercise in chronic HF patients. The instantaneous firing frequency within one cardiac interval may increase peripheral vascular tone, contributing to exercise intolerance.

\section{ASSESSMENT OF MUSCLE SYMPATHETIC NERVE ACTIVITY DURING IRREGULAR VENTRICULAR RESPONSES IN HF LIMITATIONS OF MULTIUNIT MSNA IN ARRHYTHMIA}

Arrhythmia is a common complication of chronic HF caused by arrhythmogenic substrates (Braunwald, 1997). Several studies indicated that a large multiunit MSNA burst occurred during premature ventricular contraction (PVC; Ando et al., 1997; Grassi et al., 2002) and atrial fibrillation (AF; Grassi et al., 2003; Wasmund et al., 2003) in HF patients. The low diastolic pressure induced by these arrhythmic conditions unloads arterial baroreceptors and evokes a larger and longer multiunit MSNA burst (Welch et al., 1989; Smith et al., 1995). However, only counting multiunit MSNA could cause the actual level of sympathetic nerve activity to be underestimated, because a large sympathetic activity burst could produce prolonged sympathetic inhibition. In a human study, frequent PVC and AF were recognized as exclusion criteria for evaluating sympathetic outflow by multiunit MSNA analysis. As mentioned above, total activity and/or the normalized amplitude may be useful for interindividual comparisons, but the burst amplitude and area are markedly affected by the position of the tungsten microelectrode tip. Thus, multiunit data can be difficult to compare between groups.

\section{RECORDING OF SINGLE-UNIT MSNA IN HF WITH PVC}

The mechanism underlying augmentation of the SNA in HF has been assumed to involve a disorder of arterial baroreceptors. However, recent observations indicated that arterial baroreceptor function is preserved, maintaining appropriate blood pressure in HF (Floras, 2009). Elam and Macefield (2001) demonstrated the instantaneous augmentation of multiple single-unit firing following PVC in HF patients. They reported that PVC was associated with an increase in average firing probability from $61 \%$ [in sinus

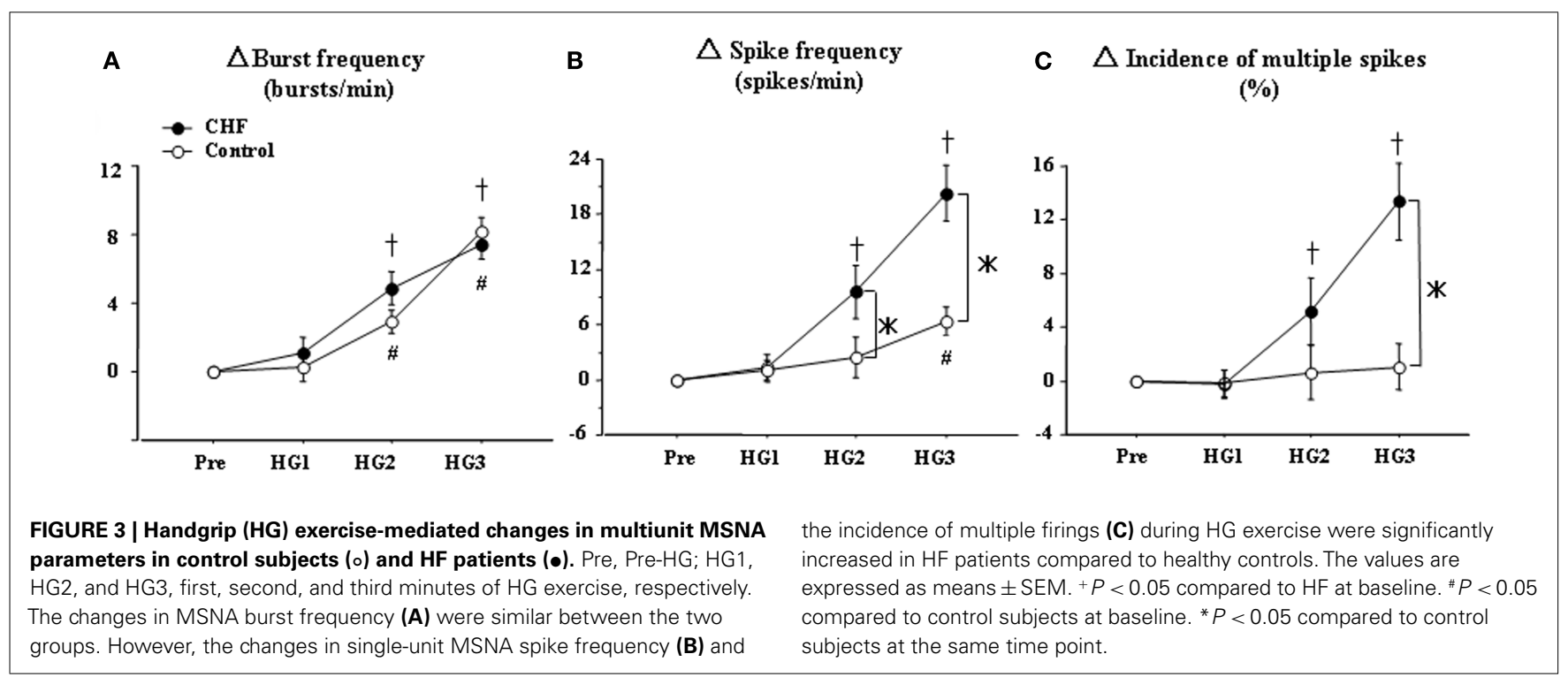


rhythm (SR)] to $80 \%$, and that the firing pattern within one cardiac interval changed to more multiple firing spikes (from 38 to $61 \%$ ). Frequent PVC is thought to induce moderate and severe left ventricular dysfunction (Baman et al., 2010). Elimination of PVC with catheter ablation has been reported to improve cardiac dysfunction (Taieb et al., 2007).

Cardiac norepinephrine spillover was reported to be related to multiple spike firing of single-unit MSNA within one cardiac interval (Lambert et al., 2011). Although the mechanisms of reduced left ventricular contraction induced by PVC remain unclear, multiple spike firing of single-unit MSNA is considered to cause the progression of heart dysfunction by instantaneous norepinephrine release to the heart.

\section{RECORDING OF SINGLE-UNIT MSNA IN HF WITH AF}

As mentioned above, the analysis of multiunit MSNA in AF is not without limitations in that a prolonged irregular ventricular response would cause a large burst followed by prolonged sympathetic inhibition. The results of previous assessments of sympathetic nerve activity in acute paroxysmal AF patients using multiunit MSNA are controversial. Grassi et al. (2003) used multiunit MSNA to assess sympathetic nerve activity during AF and $\mathrm{SR}$ in patients with paroxysmal AF and observed a reduction in SNA during AF. In contrast, Wasmund et al. (2003) found significant augmentation of multiunit MSNA during AF, which was induced by right atrial pacing. Recently, we analyzed the singleunit MSNA frequency in HF patients with AF (Ikeda et al., 2012). Multiunit MSNA, expressed as burst frequency, in HF patients with AF was decreased compared to that in HF patients with SR. However, the single-unit MSNA in HF patients with AF was significantly greater than that in HF patients with SR (62 \pm 9 vs. $42 \pm 4$ spikes $/ \mathrm{min}, P<0.05$, Figures $5 \mathrm{~A}, \mathbf{B})$. Moreover, the incidence of multiple firing of single-unit MSNA within one cardiac interval was augmented in $\mathrm{HF}+\mathrm{AF}$ patients compared to $\mathrm{HF}+\mathrm{SR}$

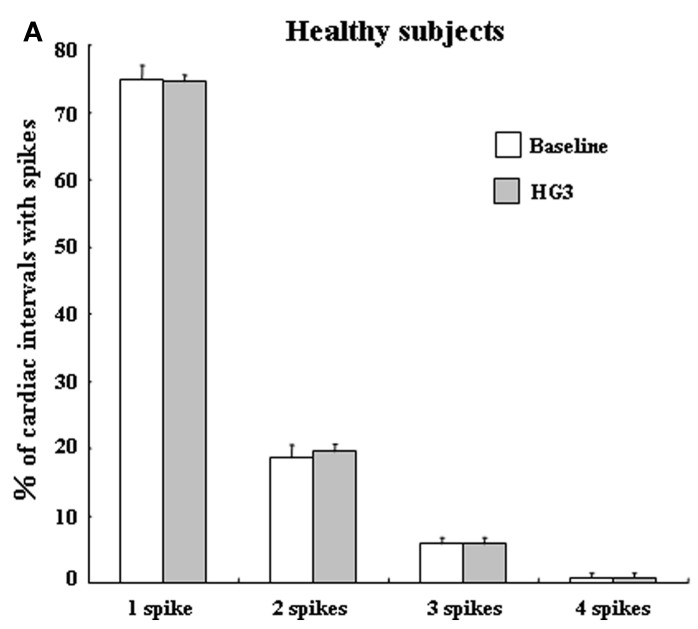

FIGURE 4 | Percentages of cardiac intervals in which 1, 2, 3, or 4 single-unit spikes fired during baseline and $\mathrm{HG} 3$ in control subjects (A) and $\mathbf{H F}$ patients (B). The percentages of multiple spike firing did not differ between baseline and $\mathrm{HG}$ exercise in healthy subjects. However, during $\mathrm{HG}$ in

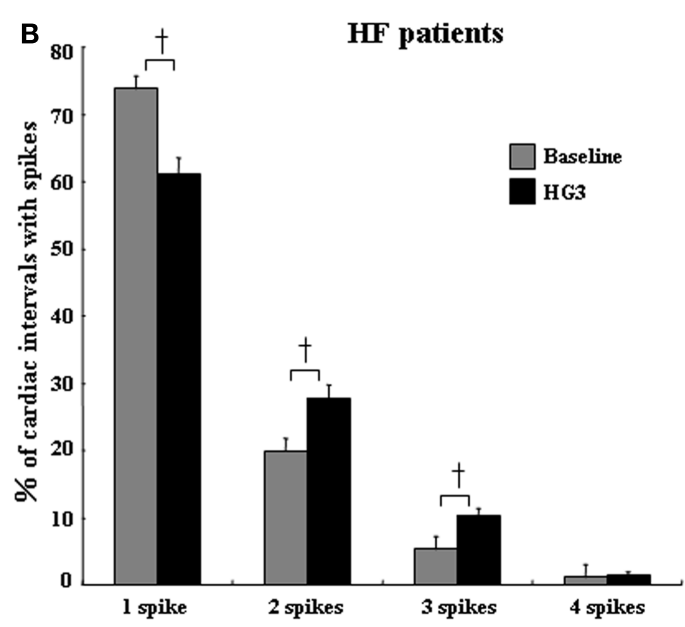

HF patients, there was a decrease in the firing probability of one spike per cardiac interval but an increase in the percentage of cardiac intervals that contained two or three spikes. All values are expressed as means \pm SEM. $+P<0.05$ compared with baseline.

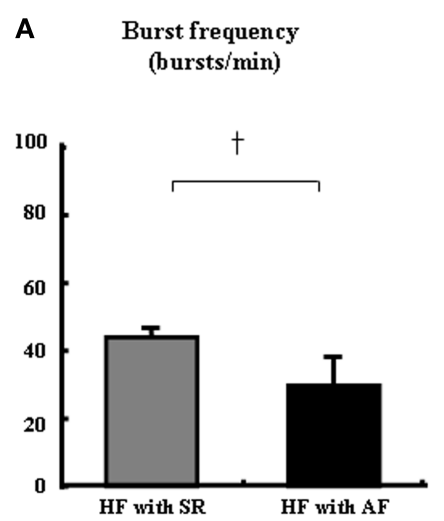

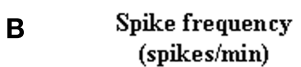

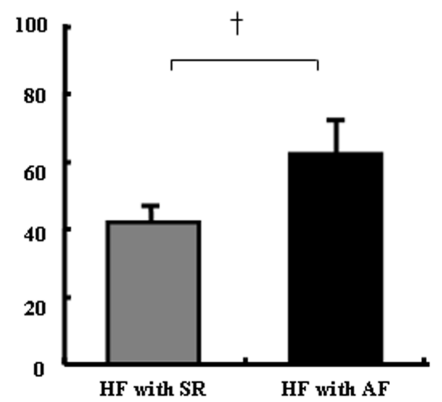

C Incidence of multiple spikes

(\%)

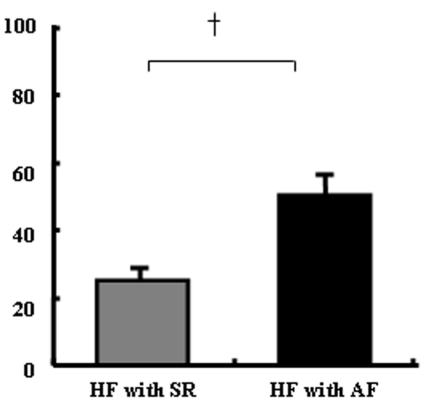

FIGURE 5 | Comparison of single-unit MSNA between HF with sinus rhythm (SR) and HF with AF. The multiunit MSNA burst frequency was significantly decreased in HF with AF compared to HF with SR (A). However, the single-unit spike frequency (B) and multiple spikes incidence (C) were significantly greater in HF with AF vs. HF with SR. All values are expressed as means \pm SEM. ${ }^{+} P<0.01$ compared to HF with SR. 


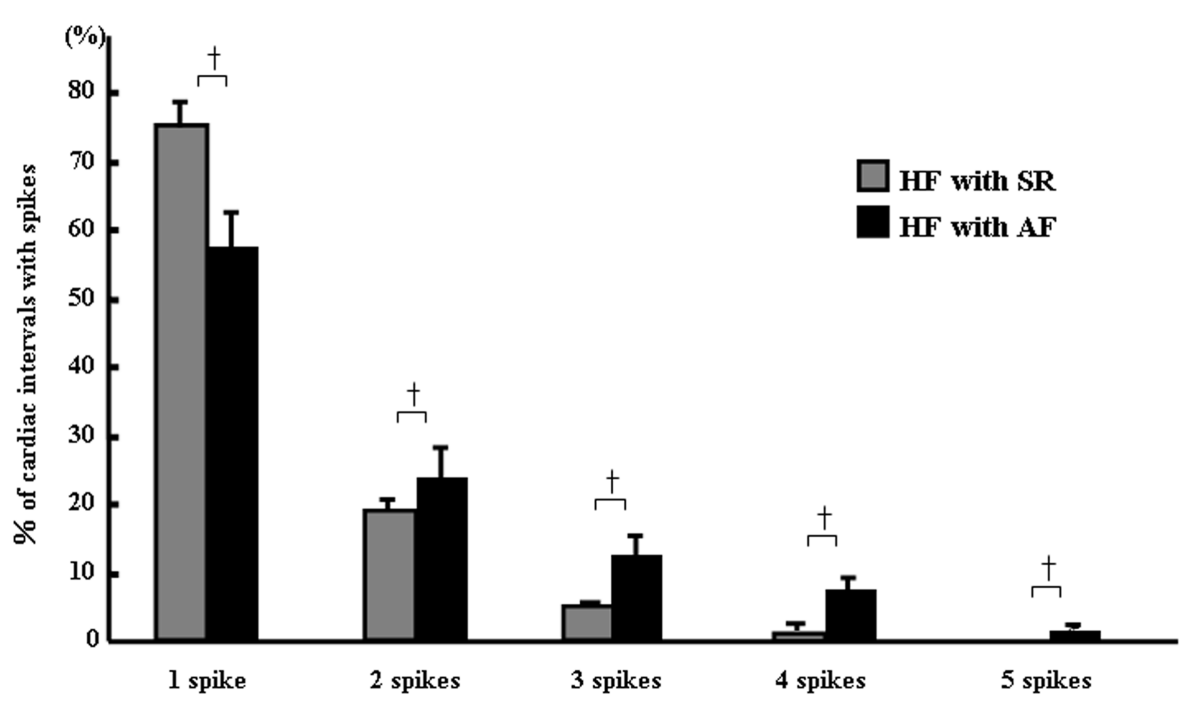

FIGURE 6 | Percentages of multiple spikes in HF with SR and AF. In HF with $A F$, the percentages of one to five spikes per cardiac interval were significantly decreased for one spike and increased for two to five spikes. All values are expressed as means \pm SEM. ${ }^{+} P<0.05$ compared to HF with SR. patients ( $48 \pm 8$ vs. $26 \pm 3 \%, P<0.01$, Figure 5 C), and it shifted toward multiple firing spikes of single-unit MSNA in HF patients with AF (Figure 6). It has been suggested that not only does HF lead to a predisposition to AF, but AF may also facilitate and worsen the development of HF. The coexistence of these cardiac disorders produces a vicious cycle, which leads to advanced pump failure in HF patients (Ehrlich et al., 2002). The data obtained in that study suggest that the instantaneous augmentation of single-unit MSNA within one cardiac interval may be attributed to the progression of heart dysfunction in HF patients with AF.

\section{CONCLUSION}

Augmented sympathetic nerve activity plays an important role in dysfunction of the heart. However, modalities for the assessment of sympathetic nerve activity in humans are limited. Moreover, the underlying differences in central sympathetic neural firing

\section{REFERENCES}

Ando, S., Dajani, H. R., Senn, B. L., Newton, G. E., and Floras, J. S. (1997). Sympathetic alternans. Evidence for arterial baroreflex control of muscle sympathetic nerve activity in congestive heart failure. Circulation 95, 316-319.

Baman, T. S., Lange, D. C., Ilg, K. J., Gupta, S. K., Liu, T. Y., Alguire, C., Armstrong, W., Good, E., Chugh, A., Jongnarangsin, K., Pelosi, F. Jr., Crawford, T., Ebinger, M., Oral, H., Morady, F., and Bogun, F. (2010). Relationship between burden of premature ventricular complexes and left ventricular function. Heart Rhythm 7, 865-869.

Barretto, A. C., Santos, A. C., Munhoz, R., Rondon, M. U., Franco, F. G., Trombetta, I. C., Roveda, F., de Matos, L. N., Braga, A. M., Middlekauff, H. R., and Negrao, C. E.
(2009). Increased muscle sympathetic nerve activity predicts mortality in heart failure patients. Int. J. Cardiol. 135, 302-307.

Bohm, M., Flesch, M., and Schnabel, P. (1997). Beta-adrenergic signal transduction in the failing and hypertrophied myocardium. J. Mol. Med. 75, 842-848.

Braunwald, E. (1997). Shattuck lecturecardiovascular medicine at the turn of the millennium: triumphs, concerns, and opportunities. N. Engl. J. Med. 337, 1360-1369.

Burke, S. L., Lambert, E., and Head, G. A. (2011). New approaches to quantifying sympathetic nerve activity. Curr. Hypertens. Rep. 13, 249-257.

Chaudhri, B., Del Monte, F., Hajjar, R. J., and Harding, S. E. (2002). Interaction between increased SERCA2a activity and beta -adrenoceptor stimulation in adult rabbit

between diseases remain unclear. Compared to the traditional recording of multiunit MSNA, the assessment of central sympathetic nerve activity to the periphery with single-unit MSNA provides additional information regarding the underlying mechanisms of sympathetic firing in chronic HF patients. In particular, the firing spike frequency and multiple spike firing within one cardiac interval are thought to contribute to disease progression and exercise intolerance in chronic HF. Therefore, these advantages of evaluation for detailed sympathetic firing pattern could improve our understanding the pathology of increased sympathetic nerve activity in clinical situation and disease progression in HF.

\section{ACKNOWLEDGMENTS}

We thank Dr. Shigeo Takata (Kanazawa Municipal Hospital) and Dr. Toyoshi Yuasa for their help with microneurography.

myocytes. Am. J. Physiol. Heart Circ. Physiol. 283, H2450-H2457.

Cohn, J. N., Levine, T. B., Olivari, M. T., Garberg, V., Lura, D., Francis, G. S., Simon, A. B., and Rector, T. (1984). Plasma norepinephrine as a guide to prognosis in patients with chronic congestive heart failure. N. Engl. J. Med. 311, 819-823.

Communal, C., Singh, K., Pimentel, D. R., and Colucci, W. S. (1998). Norepinephrine stimulates apoptosis in adult rat ventricular myocytes by activation of the beta-adrenergic pathway. Circulation 98, 1329-1334. Crisafulli, A., Salis, E., Tocco, F., Melis, F., Milia, R., Pittau, G., Caria, M. A., Solinas, R., Meloni, L., Pagliaro, P., and Concu, A. (2007). Impaired central hemodynamic response and exaggerated vasoconstriction during muscle metaboreflex activation in heart failure patients. Am. J.
Physiol. Heart Circ. Physiol. 292, H2988-H2996.

Dibona, G. F., and Sawin, L. L. (1999). Functional significance of the pattern of renal sympathetic nerve activation. Am. J. Physiol. 277, R346R353.

Ehrlich, J. R., Nattel, S., and Hohnloser, S. H. (2002). Atrial fibrillation and congestive heart failure: specific considerations at the intersection of two common and important cardiac disease sets. J. Cardiovasc. Electrophysiol. 13, 399-405.

Elam, M., and Macefield,V. (2001). Multiple firing of single muscle vasoconstrictor neurons during cardiac dysrhythmias in human heart failure. $J$. Appl. Physiol. 91, 717-724.

Elam, M., McKenzie, D., and Macefield, V. (2002). Mechanisms of sympathoexcitation: single-unit analysis of muscle vasoconstrictor neurons 
in awake OSAS subjects. J. Appl. Physiol. 93, 297-303.

Floras, J. S. (2009). Sympathetic nervous system activation in human heart failure: clinical implications of an updated model. J. Am. Coll. Cardiol. $54,375-385$.

Francis, G. S., Benedict, C., Johnstone, D. E., Kirlin, P. C., Nicklas, J., Liang, C. S., Kubo, S. H., Rudin-Toretsky, E., and Yusuf, S. (1990). Comparison of neuroendocrine activation in patients with left ventricular dysfunction with and without congestive heart failure. A substudy of the Studies of Left Ventricular Dysfunction (SOLVD). Circulation 82, 1724-1729.

Graham, L. N., Smith, P. A., Huggett, R. J., Stoker, J. B., Mackintosh, A. F., and Mary, D. A. (2004). Sympathetic drive in anterior and inferior uncomplicated acute myocardial infarction. Circulation 109, 2285-2289.

Grassi, G., Seravalle, G., Bertinieri, G., and Mancia, G. (2003). Behaviour of the adrenergic cardiovascular drive in atrial fibrillation and cardiac arrhythmias. Acta Physiol. Scand. 177, 399-404.

Grassi, G., Seravalle, G., Bertinieri, G., Stella, M. L., Turri, C., and Mancia, G. (2002). Sympathetic response to ventricular extrasystolic beats in hypertension and heart failure. Hypertension 39, 886-891.

Grassi, G., Seravalle, G., and Cattaneo, B. M. (1995). Sympathetic activation and loss of reflex sympathetic control in mild congestive heart failure. Circulation 92, 3206-3211.

Huggett, R. J., Scott, E. M., Gilbey, S. G., Bannister, J., Mackintosh, A. F., and Mary, D. A. (2005). Disparity of autonomic control in type 2 diabetes mellitus. Diabetologia 48, 172-179.

Ikeda, T., Murai, H., Kaneko, S., Usui, S., Kobayashi, D., Nakano, M., Ikeda, K., Takashima, S., Kato, T., Okajima, M., Furusho, H., and Takamura, M. (2012). Augmented singleunit muscle sympathetic nerve activity in heart failure with chronic atrial fibrillation. J. Physiol. (Lond.) 590, 509-518.

Kaufman, M. P., and Hayes, S. G. (2002). The exercise pressor reflex. Clin. Auton. Res. 12, 429-439.

Kimmerly, D. S., O'Leary, D. D., and Shoemaker, J. K. (2004). Test-retest repeatability of muscle sympathetic nerve activity: influence of data analysis and head-up tilt. Auton. Neurosci. 114, 61-71.

Lambert, E., Dawood, T., Schlaich, M., Straznicky, N., Esler, M., and Lambert, G. (2008). Single-unit sympathetic discharge pattern in pathological conditions associated with elevated cardiovascular risk. Clin. Exp. Pharmacol. Physiol. 35, 503-507.

Lambert, E., Hotchkin, E., Alvarenga, M., Pier, C., Richards, J., Barton, D., Dawood, T., Esler, M., and Lambert, G. (2006). Single-unit analysis of sympathetic nervous discharges in patients with panic disorder. $J$. Physiol. (Lond.) 570, 637-643.

Lambert, E. A., Schlaich, M. P., Dawood, T., Sari, C., Chopra, R., Barton, D. A., Kaye, D. M., Elam, M., Esler, M. D. and Lambert, G. W. (2011). Singleunit muscle sympathetic nervous activity and its relation to cardiac noradrenaline spillover. J. Physiol. (Lond.) 589, 2597-2605.

Leimbach, W. N. Jr., Wallin, B. G., Victor, R. G., Aylward, P. E., Sundlof, G., and Mark, A. L. (1986). Direct evidence from intraneural recordings for increased central sympathetic outflow in patients with heart failure. Circulation 73, 913-919.

LeJemtel, T. H., Maskin, C. S., Lucido, D., and Chadwick, B. J. (1986). Failure to augment maximal limb blood flow in response to one-leg versus two-leg exercise in patients with severe heart failure. Circulation 74 , 245-251.

Macefield, V. G., Elam, M., and Wallin, B. G. (2002). Firing properties of single postganglionic sympathetic neurones recorded in awake human subjects. Auton. Neurosci. 95, 146-159.

Macefield, V. G., Rundqvist, B., Sverrisdottir, Y. B., Wallin, B. G., and Elam, M. (1999). Firing properties of single muscle vasoconstrictor neurons in the sympathoexcitation associated with congestive heart failure. Circulation 100, 1708-1713.

Macefield, V. G., Wallin, B. G., and Vallbo, A. B. (1994). The discharge behaviour of single vasoconstrictor motoneurones in human muscle nerves. J. Physiol. (Lond.) 481, 799-809.

Mark, A. L., Victor, R. G., Nerhed, C., and Wallin, B. G. (1985). Microneurographic studies of the mechanisms of sympathetic nerve responses to static exercise in humans. Circ. Res. $57,461-469$.

Middlekauff, H. R., Nitzsche, E. U., Hoh, C. K., Hamilton, M. A., Fonarow, G. C., Hage, A., and Moriguchi, J. D. (2000). Exaggerated renal vasoconstriction during exercise in heart failure patients. Circulation 101, 784-789.

Mitchell, J. H. (2012). Neural control of the circulation during exercise: insights from the 1970-1971 Oxford studies. Exp. Physiol. 97, 14-19.

Momen, A., Bower, D., Boehmer, J., Kunselman, A. R., Leuenberger, U. A., and Sinoway, L. I. (2004). Renal blood flow in heart failure patients during exercise. Am. J. Physiol. Heart Circ. Physiol. 287, H2834-H2839.

Murai, H., Takamura, M., Maruyama, M., Nakano, M., Ikeda, T., Kobayashi, D., Otowa, K., Ootsuji, H., Okajima, M., Furusho, H., Takata, S., and Kaneko, S. (2009). Altered firing pattern of single-unit muscle sympathetic nerve activity during handgrip exercise in chronic heart failure. J. Physiol. (Lond.) 587, 2613-2622.

Murai, H., Takata, S., Maruyama, M., Nakano, M., Kobayashi, D., Otowa, K., Takamura, M., Yuasa, T., Sakagami, S., and Kaneko, S. (2006) The activity of a single muscle sympathetic vasoconstrictor nerve unit is affected by physiological stress in humans. Am. J. Physiol. Heart Circ. Physiol. 290, H853-H860.

Negrao, C. E., Rondon, M. U., Tinucci, T., Alves, M. J., Roveda, F., Braga, A. M., Reis, S. F., Nastari, L., Barretto, A. C., Krieger, E. M., and Middlekauff, H. R. (2001). Abnormal neurovascular control during exercise is linked to heart failure severity. Am. J. Physiol. Heart Circ. Physiol. 280, H1286-H1292.

Notarius, C. F., Ando, S., Rongen, G. A., and Floras, J. S. (1999). Resting muscle sympathetic nerve activity and peak oxygen uptake in heart failure and normal subjects. Eur. Heart J. 20 , 880-887.

Notarius, C. F., Atchison, D. J., and Floras, J. S. (2001). Impact of heart failure and exercise capacity on sympathetic response to handgrip exercise. Am. J. Physiol. Heart Circ. Physiol. 280, H969-H976.

Piepoli, M., Clark, A. L., Volterrani, M., Adamopoulos, S., Sleight, P., and Coats, A. J. (1996). Contribution of muscle afferents to the hemodynamic, autonomic, and ventilatory responses to exercise in patients with chronic heart failure: effects of physical training. Circulation 93 , 940-952.

Smith, M. L., Ellenbogen, K. A., and Eckberg, D. L. (1995). Baseline arterial pressure affects sympathoexcitatory responses to ventricular premature beats. Am. J. Physiol. 269, H153-H159.

Sterns, D. A., Ettinger, S. M., Gray, K. S., Whisler, S. K., Mosher, T. J., Smith, M. B., and Sinoway, L. I. (1991). Skeletal muscle metaboreceptor exercise responses are attenuated in heart failure. Circulation 84 2034-2039.

Sundlof, G., and Wallin, B. G. (1977). The variability of muscle nerve sympathetic activity in resting recumbent man. J. Physiol. (Lond.) 272, 383-397.
Taieb, J. M., Maury, P., Shah, D., Duparc, A., Galinier, M., Delay, M., Morice, R., Alfares, A., and Barnay, C. (2007). Reversal of dilated cardiomyopathy by the elimination of frequent left or right premature ventricular contractions. J. Interv. Card. Electrophysiol. 20, 9-13.

Vallbo, A. B., Hagbarth, K. E., Torebjork, H. E., and Wallin, B. G. (1979). Somatosensory, proprioceptive, and sympathetic activity in human peripheral nerves. Physiol. Rev. 59, 919-957.

Wasmund, S. L., Li, J. M., Page, R. L., Joglar, J. A., Kowal, R. C., Smith, M. L., and Hamdan, M. H. (2003). Effect of atrial fibrillation and an irregular ventricular response on sympathetic nerve activity in human subjects. Circulation 107, 2011-2015.

Welch, W. J., Smith, M. L., Rea, R. F., Bauernfeind, R. A., and Eckberg, D. L. (1989). Enhancement of sympathetic nerve activity by single premature ventricular beats in humans. $J$. Am. Coll. Cardiol. 13, 69-75.

Williamson, J. W., Fadel, P. J., and Mitchell, J. H. (2006). New insights into central cardiovascular control during exercise in humans: a central command update. Exp. Physiol. 91, 51-58.

Zelis, R., Longhurst, J., Capone, R. J., and Mason, D. T. (1974). A comparison of regional blood flow and oxygen utilization during dynamic forearm exercise in normal subjects and patients with congestive heart failure. Circulation 50, 137-143.

Conflict of Interest Statement: The authors declare that the research was conducted in the absence of any commercial or financial relationships that could be construed as a potential conflict of interest.

Received: 03 March 2012; paper pending published: 18 March 2012; accepted: 03 April 2012; published online: 03 May 2012.

Citation: Murai H, Takamura $M$ and Kaneko S (2012) Advantage of recording single-unit muscle sympathetic nerve activity in heart failure. Front. Physio. 3:109. doi: 10.3389/fphys.2012.00109

This article was submitted to Frontiers in Integrative Physiology, a specialty of Frontiers in Physiology.

Copyright $\odot 2012$ Murai, Takamura and Kaneko. This is an open-access article distributed under the terms of the Creative Commons Attribution Non Commercial License, which permits noncommercial use, distribution, and reproduction in other forums, provided the original authors and source are credited. 